\title{
A DUCTED WIND TURBINE SIMULATION MODEL FOR BUILDING SIMULATION
}

\author{
Andy Grant ${ }^{\#}$ BSc,PhD Nick Kelly, BEng MSc PhD* \\ \#Energy Systems Research Unit, University of Strathclyde, Scotland \\ *Scottish Energy Environment Foundation (corresponding author) \\ e-mail: andy@esru.strath.ac.uk,nick@seef.org.uk \\ Tel: +44 (0)141548 2854 Fax: +44 (0)1415525105
}

\begin{abstract}
Power production is shifting away from centralised generation plants to production of heat and power at the point of demand. A technology that may play a part in this shift is the ducted wind turbine (DWT). The emergence of small building integrated micro turbines opens up the possibility of utilising the differential pressures occurring around buildings for local power production. This paper describes work to develop and test a simple mathematical model of a ducted wind turbine and its integration within a building simulation tool. A case study in which the simulation model will be used to analyse of the likely power output from a building incorporating ducted wind turbines within the façade is also presented.
\end{abstract}

Keywords: ducted wind turbine, mathematical model, embedded generation, building simulation.

A previous version of this paper appears in the proceedings of Building Simulation 2003 (1). 


\section{INTRODUCTION}

As we move into the $21^{\text {st }}$ century technological innovation is changing the means by which heat and power can be delivered to the built environment. New "micro-grid" type technologies offer the potential of supplying heat and power locally from "clean" and energy- efficient-type technologies. Examples of these technologies include micro-CHP using Stirling engines, photovoltaics (PV) and fuel cells.

To assess the effectiveness of these devices and also to assess the impact of their diffusion into the built environment it is necessary to develop models to simulate their performance in a realistic operational context. Building simulation offers a means to do this and can reveal important performance characteristics such as the total energy yield, the temporal characteristics of heat and power output and the compatibility of renewable supplies with loads.

The ducted wind turbine (DWT) is an emerging micro-grid technology; it is a small, wind energy conversion device that can be integrated into the façade of a building and may be a useful means of producing power in urban areas with windier climates. The ducted wind turbine overcomes many of the problems associated with the use of conventional wind turbines in an urban environment, which are hampered by high levels of turbulence in the air stream, and are also constrained by concerns over visual impact, noise and public safety. In contrast DWT units are purposely designed for attachment to buildings and are both robust and unobtrusive.

This paper describes the integration of a simple DWT model (2) into a building simulation tool.

\section{WIND POWER IN URBAN ENVIRONMENTS}

Airflow in the urban environment is a complex 3-dimensional phenomena which is highly turbulent, transient and very difficult to model. Characteristics of urban sir flow include the formation of turbulent wakes and vortices and channelling of wind into "canyons". 
Because of the turbulent and unsteady nature of urban airflow the use of wind power for the local generation of electrical power has been largely overlooked for conventional wind energy conversion devices. High levels of turbulence can lead to problems with vibration and other transient structural loadings on the blades and tower, which can significantly shorten the life of turbines.

Other problems with conventional wind turbines include:

- they are visually obtrusive;

there is the potential for noise pollution; and

a they are difficult to integrate into the building structure as they require bracing and larger machines require a massive base (usually a large concrete foundation).

All of these problems have tended to rule out wind power as a viable source of urban energy production

\section{THE DUCTED WIND TURBINE}

The small ducted wind power device described in this paper has been developed from a design patented in the late 70 's ${ }^{1}$, which can make use of the pressure differentials around a building. Unlike conventional wind turbines, the ducted wind turbine (DWT) was specifically developed with the idea of integration of wind power into the built environment.

The big differences between DWTs and conventional wind turbines are (i) it is a vertical axis wind turbine (VAWT) and (ii) that the blades are fully enclosed. Enclosure of the blades in a duct has several advantages:

\footnotetext{
${ }^{1}$ Webster G W. Devices for utilising the power of the wind; 1979, USA Patent No. 4154556.
} 
ㅁ blade shedding is not a problem;

a the power capture potential for a ducted turbine is higher than that of a conventional turbine as there are higher pressure differences and velocities across the rotor (described later); and

a aWTs are small and fully enclosed they are more easily integrated into a building façade and are less visually obtrusive.

Note however that DWTs in the form presented here are very much an embryonic technology and only prototype machines exist.

\section{Figure 2 a cross section through the DWT.}

On the flat roofed building of there is a positive pressure on the vertical surface, while the separation of flow due to the sharp edge of the roof means there is a significant negative pressure, creating a strong pressure differential at the roof leading edge (figure 1). This is the optimum siting point for a ducted wind turbine (note a pressure differential also occurs at vertical edges).

\section{THE DWT MODEL}

The simulation model described in this paper has been derived from a design (figure 2 and 3 ) that attaches to the roof edge of rectangular-section buildings, making use of the pressure differentials shown in figure 1 . Note that the spoiler shown in figure 2 is added to increase the pressure difference across the device. The validated model has been constructed for one-dimensional flow (2) and can be used to determine the potential for power production from such a device.

Figure 3 a picture of a prototype DWT.

In a uniform unobstructed duct the induced air velocity $U_{2}$ will be: 


$$
U_{2}=C_{v} \sqrt{\frac{2\left(P_{1}-P_{2}\right)}{\rho}}
$$

$P_{1}$ is the stagnation pressure at the duct inlet and $P_{2}$ is the static pressure at the duct outlet.

A differential pressure coefficient can be defined such that:

$$
\delta=\frac{\left(P_{1}-P_{2}\right)}{\frac{1}{2} \rho V_{\infty}^{2}}
$$

And equation (1) can be re-written as:

$$
U_{2}=C_{v} \sqrt{\delta} V_{\infty}
$$

If a turbine is placed in the duct causing a pressure drop $\Delta P_{T}$ then the equation for the induced velocity is:

$$
\begin{aligned}
U_{2} & =C_{v} \sqrt{\frac{2\left(P_{1}-P_{2}-\Delta P_{T}\right)}{\rho}} \\
\therefore U_{2} & =C_{v} \sqrt{\delta U_{\infty}^{2}-\frac{2 \Delta P_{T}}{\rho}}
\end{aligned}
$$

The work extracted by the turbine from the air stream is given by

$$
W_{T}=\dot{Q}_{T} \Delta P_{T}
$$

Here $Q_{T}$ is the air flow rate through the turbine, which can be expressed as 


$$
\dot{Q}_{T}=\rho A U_{2}
$$

Rearranging equation 4 for $\Delta P_{T}$ and substituting into equation 5 gives the following expression for the work extracted from the air stream:

$$
W_{T}=\rho A U_{2}\left[\frac{\delta U_{\infty}^{2}}{2}-\frac{U_{2}^{2}}{2 C_{v}^{2}}\right]
$$

Differentiating Equation 7 with respect to $U_{2}$ gives the maximum power condition:

$$
U_{2}=C_{v} \sqrt{\frac{\delta}{3}} \cdot U_{\infty}
$$

Substituting this into Equation 7 gives the maximum power output:

$$
W_{T \max }=\frac{C_{v}}{3 \sqrt{3}} \rho A \delta^{3 / 2} U_{\infty}^{3}
$$

\section{Figure 4 a simple model of a ducted wind energy conversion device.}

The power output of the component is therefore a function of the duct velocity coefficient $\left(C_{v}\right)$, the opening area $A$ and the free stream velocity of the wind, $U_{\infty}$. Experimental analysis (2) has shown $C_{v}$ to be close to 1.0

Equation 9 can be re-arranged to give the power output in terms of a power coefficient $\mathrm{C}_{\mathrm{P}}$ and the available power in the wind $P_{w}$, which is defined as:

$P_{w}=\frac{1}{2} \rho A U_{\infty}^{3}$

By inspection of equation 9 the power coefficient is: 
$C_{p}=\frac{2}{3 \sqrt{3}} C_{v} \delta^{3 / 2}$

And the power extracted from the air stream is:

$W_{T \max }=C_{p} P_{w}$

Figure 5 shows the variation in $C_{P}$ with the pressure coefficient differential across the turbine.

\section{Figure 5 the variation of $\mathrm{C}_{\mathrm{P}}$ with $\delta$.}

In conventional wind turbines the power coefficient peaks around 0.593 (the Betz limit). However it is clear from figure 5 that power coefficients considerably greater than the Betz limit are obtainable for ducted wind turbines if losses in the duct are kept to a reasonable minimum.

The reason for this is that the achievable pressure differential across the DWT, $\Delta P$, is far higher than that achievable with a conventional wind turbine. This is due to the fact that for the DWT the $\Delta P$ is being created by the airflow over the building, whereas in a conventional turbine the $\Delta P$ is caused by the airflow across the blades themselves.

\section{INTEGRATION WITH BUILDING SIMULATION}

Equation 9 forms the basis of the DWT model that has been integrated into the ESP-r (3) building simulation tool as a building-integrated renewable energy component. Examples of other renewable components that already exist in the tool include solar collectors and photovoltaics. These components utilise boundary condition data provided by ESP-r (solar radiation, temperature, etc.) to calculate their heat and/or power output. They can be fully integrated within an ESP-r building simulation model. For example the PV model is defined as a component of the building fabric, which interacts with both the thermal and electrical domains of an ESP-r model (4). 
In a similar fashion, to calculate its power output, the DWT model uses the wind velocity and direction, and ESP-r's calculation of inlet and outlet surface pressure coefficients $\delta_{i}$ and $\delta_{o}$ respectively.

These pressure coefficients and their differential $\delta$ (used in equations 7,8,9 and 11) are derived from the pressure difference, $\Delta P$, (based on stagnation pressures) across the inlet and outlet surfaces of the DWT:

$\Delta P=\frac{1}{2}\left(\delta_{i} \rho U_{\infty}^{2}-\delta_{o} \rho U_{\infty}^{2}\right)$

The differential pressure coefficient is therefore:

$\delta=\delta_{i}-\delta_{o}$

It follows that the pressure difference across the DWT can be found from:

$\Delta P=\frac{1}{2} \delta \rho U_{\infty}^{2}$

In locating a DWT on a building, the aim therefore is to maximise the value of $\delta$, the pressure coefficient differential across the ends of the duct. The duct inlet is placed in a region where the pressure coefficient is close to unity (not difficult in practice); for the outlet a large negative coefficient is desirable. As mentioned previously, in flat roofed buildings the maximum pressure differential will occur at the leading edge of the roof where wind flow typically generates pressure coefficient in the range -1 to -1.5 (5). Where the roof is pitched, the lowest pressures are found immediately downwind of the ridge-line. The presence of the DWT may of course influence the local flow patterns and affect the values of pressure coefficients, but it should be possible to achieve $\delta$ values of 1.5 in a well-designed installation. 
It is important therefore to be able to predict with accuracy the pressure coefficients over the surfaces of the building, so that the power output and energy capture of the DWT may be estimated. Predictions must cover a wide range of incident angles to the building facade, so that directional sensitivity may be determined.

ESP-r can calculate values of $\delta_{\mathrm{i}}$ and $\delta_{\mathrm{o}}$ and supply them to the DWT model so that $\delta$ can be calculated. To achieve this the DWT component is linked to two surfaces on the ESP-r building model (figure 4). At any time $t$ during a simulation ESP-r's calculated values of $\delta_{\mathrm{i}}$ and $\delta_{\mathrm{o}}$ for these surfaces, and the value of the free stream wind velocity, $\mathrm{U}_{\infty}$, held in the simulation climate file are fed into the DWT model, which then calculates the turbine work output.

\section{Figure 6 integration of the DWT model into a building model.}

\section{CLIMATE DATA}

The output of all of ESP-r's renewable energy components is heavily influenced by the climate data that provides the boundary conditions for their solution. ESP-r simulations generally use hourly averaged climate data. In the case of the solar energy components (PV and solar thermal collectors) the output is largely a linear function of the solar intensity falling on the component and so the use of the use of averaged data is not a problem.

In the case of the DWT model the power output is influenced by the local wind speed and direction and power output is a function of the cube of the incident free stream wind speed. So the model will be particularly sensitive to higher speeds, which have a disproportionate impact on the power output. Around buildings in the urban environment such high speeds frequently occur in short duration "gusts". 
Gusting is a manifestation of the high levels of turbulence, e.g. over 30\% turbulent intensity (6), found in the so-called "urban canopy". High turbulence levels lead to significant, high-frequency changes in both wind direction and speed.

As mentioned previously, the data used in building simulation tools is usually time-averaged, hourly data, often collected at rural weather stations, where the local microclimate and characteristics of the atmospheric boundary layer are often very different to that found in urban areas. This is problematic for the DWT model. Firstly, the use of time-averaged data will filter out effects such as wind gusting, which will impact on the power output calculations of the model. Secondly, the wind speed data is often recorded at a different height to that which DWTs may be located on a building. Consequently, direct use of "raw" climate data as read from a simulation climate file may give misleading results as to the potential for power output from the DWT device ${ }^{2}$.

Various techniques have been developed to overcome these problems. The effect of height differences between the measurement point and the location of a simulation component on the wind velocity is often addressed by adjusting the measured data according to an assumed wind velocity profile. An example is the power law profile (7):

$$
\frac{U_{l}}{U_{10}}=K z_{l}^{a}
$$

However, profiles must be applied with caution, particularly in urban environments, where their use is often inappropriate, as wind patterns at within the urban canopy may be dominated by neighbouring buildings.

The use of CFD is a useful means of gauging the impact of surrounding buildings (including the building itself) on the local airflow direction and speeds in relation to the prevailing direction and

\footnotetext{
2 It should also be noted that the arguments put forward here relating to hourly averaged wind data also apply to infiltration models.
} 
speed. (8) has used CFD to generate the local wind speeds and pressure coefficient differentials required by the DWT model for a particular building.

To overcome the filtering out of short-duration changes in wind speed and direction the DWT model has been equipped with an efficient statistical model, which takes the averaged free stream wind speed and direction in the climate file and an assumed value of the local turbulent intensity to calculate a distribution of wind speed and direction about their mean values; this distribution is then used by the DWT model to calculate power output over the simulation time step.

Note that this statistical approach does not give a picture of the short-term temporal variation in power output as would be provided by the use of high-frequency monitored wind data with the model. The use of such data would be necessary if the model was to be used in power quality analysis.

To calculate the distribution of wind speeds and the wind directions about their mean values the two readings $\left[\bar{U}_{\infty}, \theta\right]$ are recast into two component velocities:

$\bar{u}=U_{\infty} \sin \theta$

$\bar{v}=U_{\infty} \cos \theta$

The instantaneous values of these two components is given by

$u=\bar{u}+u^{\prime}$

$v=\bar{v}+v^{\prime}$

Where the barred values are the components of the mean wind speed and the dashed values are fluctuating velocities ${ }^{3}$. The instantaneous values of the two components are assumed to follow a

3 The fluctuation of the $\mathrm{z}$ component is not considered as a) the model is insensitive to the $\mathrm{z}$ component of velocity and b) this information is not contained in the ESP-r climate file. 
normal distribution about the mean speed, which can be described using the following standard probability density function:

$$
f(\mathbf{u})=\frac{1}{\sigma_{\mathbf{u}} \sqrt{2 \pi}} \exp \left[-\frac{1}{2}\left(\frac{\mathbf{u}-\overline{\mathbf{u}}}{\sigma_{\mathbf{u}}}\right)^{2}\right]
$$

The standard deviation, $\sigma$, can be expressed in terms of the turbulent intensity $(I)$ of the air flow. Turbulent intensity is defined as (9):

$$
I=\frac{\sqrt{\overline{u^{\prime 2}}+\overline{v^{\prime 2}}+\overline{z^{\prime 2}}}}{3 U_{\infty}}
$$

Now in turbulent flow the root mean squared value of fluctuations in all directions are assumed to be identical so that the turbulent intensity can be expressed as:

$I=\frac{\sqrt{\overline{\mathbf{u}^{\prime 2}}}}{U_{\infty}}=\frac{\sqrt{\frac{1}{n} \sum_{i=1}^{n}(\mathbf{u}-\overline{\mathbf{u}})}}{U_{\infty}} \cong \frac{\sigma_{\mathbf{u}}}{U_{\infty}}$

Where $n$ is the number of readings of a particular velocity component $\mathbf{u}(\mathbf{u}=\mathrm{u}, \mathrm{v}$ or $\mathrm{w})$ over a period of time. Equation 21 is valid if $n$ is large. The standard deviation of the velocity component $\mathbf{u}$ can therefore be re-expressed in terms of the turbulent intensity $I$ and the free stream velocity:

$\sigma_{\mathbf{u}}=I U_{\infty}$

The probability density function for each velocity component can therefore be re-written in terms of the turbulent intensity and the free stream velocity. 
$f(\mathbf{u})=\frac{1}{I U_{\infty} \sqrt{2 \pi}} \exp \left[-\frac{1}{2}\left(\frac{\mathbf{u}-\overline{\mathbf{u}}}{I U_{\infty}}\right)^{2}\right]$

The actual probability of wind speeds occurring over a range $[\mathrm{a}, \mathrm{b}]$ is given by:

$$
p=\int_{\mathbf{u}=a}^{\mathbf{u}=b} f(\mathbf{u}) d \mathbf{u}
$$

The effect of changing the turbulent intensity of the air flow in Equation 23 is shown in figure 7. Increasing $I$ increases the spread of velocities and reduces the height of the probability density curve at the mean wind speed.

\section{Figure 7 the effect of changing $I$ in Equation 23.}

Equation 23 is embedded in the DWT model. At each simulation time step the model makes $n$ samples and calculates the probability density and then probabilities of a range of $u$ and $v$ values, and the combinatorial probabilities of $[\mathrm{u}, \mathrm{v}]$ pairs.

The range of velocities explored about the mean is $\mathbf{u} \pm 3 \sigma_{\mathbf{u}}=\mathbf{u} \pm 3 I U_{b c}$. A 3-D distribution of the time duration for a range of wind speeds and directions can then be developed for each time step based on the turbulent intensity. The time duration of each $[\mathrm{u}, \mathrm{v}]$ pair is given by:

$$
t_{u, v}=p(u, v) \times \Delta t
$$

Where $p(u, v)$ is the probability for the particular instance of $\mathrm{u}$ and $\mathrm{v}$ occurring together. $\Delta \mathrm{t}$ is the simulation time step length. The wind velocity components $u$ and $v$ are then re-cast as a speed and direction $\left(U_{i}, \theta_{i}\right)$, and these, together with their time duration and ESP-r's calculation of the pressure coefficient differential associated with $\left(U_{i}, \theta_{i}\right), \delta_{(U i, \theta i)}$, can then be passed to Equation 9 to calculate the turbine energy output for that particular combination of $u$ and $v$ and time interval $\Delta t$. The average 
power output of the turbine over the time step is the sum of the energy calculations for each $[\mathrm{u}, \mathrm{v}]$ pair divided by the simulation time step length.

\section{CASE STUDY}

This case study illustrates the use of the DWT model within the ESP-r building simulation tool and also highlights some of the issues raised in relation to the use of averaged climate data sets with the model.

The DWT has been integrated into a cube-shaped building, which has a floor area of $100 \mathrm{~m}^{2}$, is $10 \mathrm{~m}$ high and assumed to be located in a city centre, hence the surfaces for which $\delta$ is calculated (using values from ESP-r's pressure coefficients database) are assumed to be semi-sheltered. A total of eighty ducted DWTs are attached to the North, South, East and West facades of the building. Each turbine has an inlet face area of $0.2 \mathrm{~m}^{2}$ and a cut-in wind speed of $4 \mathrm{~ms}^{-1}$. For the purposes of comparison the building also features an unventilated south-facing photovoltaic façade. The façade contains $200 \mathrm{PV}$ panels with a peak power output of $12.5 \mathrm{~kW}$. However the usual power output of the façade is likely to be much lower given the low radiation levels experienced for most of the year in the UK. The output of the façade will be compared to that of the DWTs.

In these simulations the power output of the ducted wind turbines and the PV facade is calculated over the course of a year using the UK average climate data set. Five simulations were run to illustrate the effects of wind speed averaging, the statistical wind speed data manipulation described previously and turbulent intensity on the performance of the DWT model. It is assumed that In the first simulation the only the hourly averaged data values held in the climate file are used. In the following simulations the wind speed data is manipulated using the statistical method described with turbulent intensities of 5 , 10, 20 and 30\% respectively. These turbulent intensities can be regarded as ranging from high $(30 \%)$ to low values $(5 \%)$. 
Figure 8 shows the energy output from the simulations. Energy yields vary from 800 to over 1400 $\mathrm{kWh}$. Clearly there are considerable differences in these predictions, with simulations 2,34 and 5 producing $0.5 \%, 6 \%, 26 \%$ and $60 \%$ more electrical energy output respectively than simulation 1 , illustrating the effect of the statistical model and particularly the value of turbulent intensity $(I)$. This is seen to have a critical impact on the predictions of power output from the model with simulation 5 $(I=30 \%)$ predicting $59 \%$ more electrical production than simulation 2 with $I=5 \%$.

Figure 9 shows the impact of the different simulations on the total power output from the turbines over the course of the simulation period. The statistical manipulation of the wind speed slightly increases the occurrence of high power outputs, while slightly reducing the occurrence of low power outputs. This effect increases with the value of turbulence intensity and is as would be expected: a high turbulent intensity increases the likelihood of higher velocity gusts while reducing the occurrence of wind speeds at the mean.

Figure 10 shows the contribution of the different facades of the building to the total electrical energy production. The prevalent wind direction is approximately from the south-west, so the bulk of the power produced is from the south and west facade. This pattern is unaffected in the five simulations.

Analysis has shown that the generator attached to the DWT has an efficiency of around $65 \%$ over a range of rotational speeds (10). Using this value, the average energy yield predicted for the DWT components is around $55-90 \mathrm{kWh} / \mathrm{m}^{2}$, the higher power outputs occurring with greater turbulent intensity. Note that the positioning of the DWTs has not been optimised in this simulation.

For those DWTs positioned towards the prevailing wind the annual energy yield is around 125-170 $\mathrm{kWh} / \mathrm{m}^{2}$, while for those on the north façade the energy yield is only $30 \mathrm{kWh} / \mathrm{m}^{2}$. 


\section{COMPARISON WITH PV OUTPUT}

The total power output from the PV façade over the course of the year is some $8240 \mathrm{kWh}$. While this is significantly higher than that obtained from the DWTs the energy density of the DWTs facing the prevailing wind (at higher levels of turbulent intensity) is higher than that of PV (the energy density of PV is around $90 \mathrm{kWh} / \mathrm{m}^{2}$ ). However as this study illustrates the available locations for DWTs are more restricted hence total power output will be less than for a PV facade. These findings are similar to those from previous comparisons (11).

Figure 10 the contributions from the different facades to power production.

\section{FIELD TRIALS}

Field trials have been conducted on number of small prototype DWT units with a rotor diameter of $0.5 \mathrm{~m}$. These have been mounted individually on rooftops and power coefficients of up to 0.3 have been obtained. In stand alone mode the turbine has been seen to tolerate $20-30$ degrees of misalignment with the incident wind without significant loss of power. Monitoring continues to determine annual energy yield from the devices.

In addition to the field trials several ducted wind turbines have been installed on the Lighthouse building in the centre of Glasgow. These are shown in figure 11

\section{Figure 11 Ducted wind turbines on the Lighthouse building, Glasgow}

\section{CONCLUSIONS}

This paper has outlined the basis for a simple ducted wind turbine (DWT) model and demonstrated how it has been integrated into the ESP-r building simulation tool. 
The model is sensitive to wind speed and a statistical technique using the wind turbulent intensity is employed to account for the effect of short duration, high velocity wind gusts on the power output. This effect that would otherwise be lost using hourly averaged data.

Several simulations were conducted and showed that accounting for gust effects leads to a significant increase in power output predictions from the model.

The simulated average energy yield compares favorably to that of photovoltaic materials, indicating that the ducted wind turbine shows potential as a micro-grid power source and deserves much more investigation.

\section{REFERENCES}

1. Grant AD, Kelly NJ. Development of a Ducted Wind Turbine Simulation Model: Proceedings of the eighth international IBPSA conference, Netherlands. International Building Performance Simulation Association, 2003: 407-414.

2. Grant AD, Dannecker R K and Nicolson CD. Development of building-integrated wind turbines: Proceedings of the World Wind Energy Conference, Berlin. WIP, 2002

3. Clarke JA. Energy simulation in building design. $2^{\text {nd }}$ ed. London: Butterworth-Heinemann, 2001

4. Kelly NJ, Clarke J A. Integrating power flow modelling with building simulation. Energy and Buildings, 2001; 33(4): 333-40.

5. BRE Digest 346: The Assessment of Wind Loads, Part 6: Loading coefficients for typical building. Garston, UK: Building Research Establishment, 1989.

6. Feranec T, Feranec V. Wind load on buildings and structures in groups: Proceedings of the $39^{\text {th }}$ International Conference in Experimental Stress analysis. Technical University of Prague, Czech Republic. 2001. 
7. Liddament MW. Air infiltration calculation techniques - an applications guide. Bracknell, UK: IEA Air Infiltration And Ventilation Centre (AIVC), 1986.

8 Danneker R. Wind energy in the built environment: an experimental and numerical investigation of a building integrated ducted wind tubine module. $\mathrm{PhD}$ Thesis. Glasgow: University of Strathclyde, 2001.

9. Schlichting H. Boundary layer theory. $6^{\text {th }}$ Ed. New York: McGraw Hill, 1968.

10. Ewen S, Analysis of a vertical axis ducted wind turbine. BEng Thesis. Glasgow: University of Strathclyde, 1999

11. Clarke J A, Johnstone CM, Macdonald IA, French P, Gillan S, Glover C, Tatton D, Devlin J and Mann R. The deployment of photovoltaic components within the lighthouse building in Glasgow: Proceedings of the 16th European Photovoltaic Solar Energy Conference, Glasgow. WIP, 2000.

\section{NOMENCLATURE}

$\begin{array}{lll}a, K & \text { coefficients for calculation of wind } & \text { - } \\ & \text { speed from a profile } & \mathrm{m}^{2} \\ C_{v} & \text { duct area } & \text { duct velocity coefficient } \\ I & \text { Turbulence intensity } & \\ P_{W} & \text { Power contained in the wind } \\ P(u, v) & \text { probability of velocity }\end{array}$




\begin{tabular}{|c|c|c|}
\hline$n$ & number of samples in a time step & - \\
\hline$t, \Delta t$ & time, timestep length & $\mathrm{s}$ \\
\hline$u, v$ & velocity components & $\mathrm{m} / \mathrm{s}$ \\
\hline $\bar{u}, \bar{v}$ & Average velocity components & $\mathrm{m} / \mathrm{s}$ \\
\hline$u^{\prime}, v^{\prime}$ & fluctuating velocity components & $\mathrm{m} / \mathrm{s}$ \\
\hline$z, z_{l}$ & velocity component, height & \\
\hline $\mathbf{u}$ & general velocity component & $\mathrm{m} / \mathrm{s}$ \\
\hline$U_{\infty}, U_{l}$ & $\begin{array}{l}\text { free stream wind speed, wind } \\
\text { speed at height } l\end{array}$ & $\mathrm{~m} / \mathrm{s}$ \\
\hline$U_{10}$ & measured wind speed & $\mathrm{m} / \mathrm{s}$ \\
\hline$W_{T}$ & work extracted by turbine & $\mathrm{W}$ \\
\hline$\delta$ & pressure coefficient differential & - \\
\hline$\theta$ & wind direction & o \\
\hline$\rho$ & density & $\mathrm{kg} / \mathrm{m}^{3}$ \\
\hline$\sigma$ & standard deviation & - \\
\hline
\end{tabular}




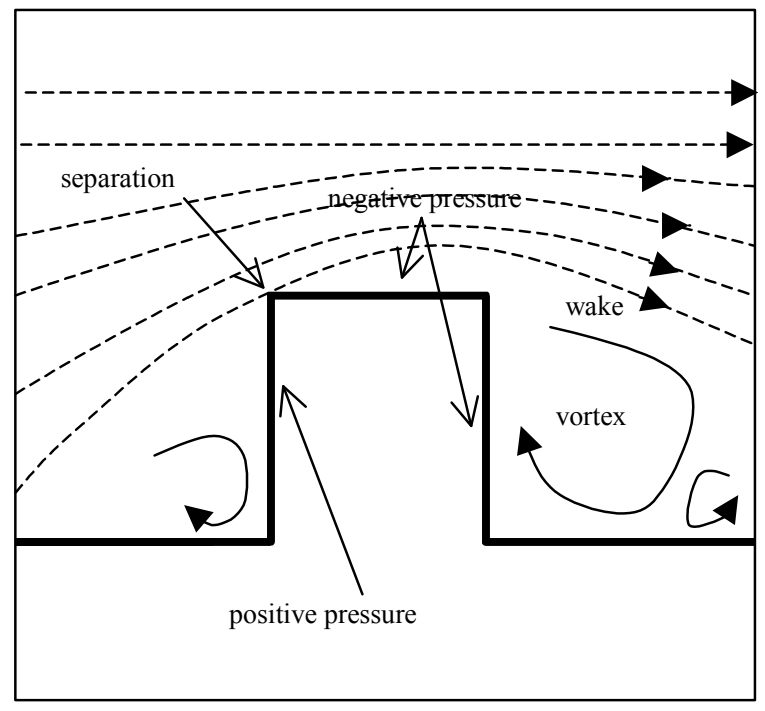

Figure 1 flow around a simple building.

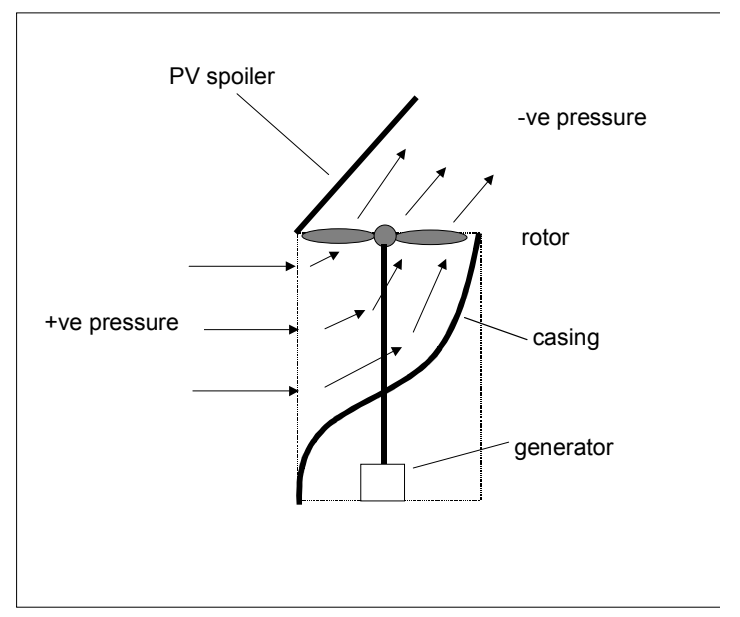

Figure 2 a cross section through the DWT. 


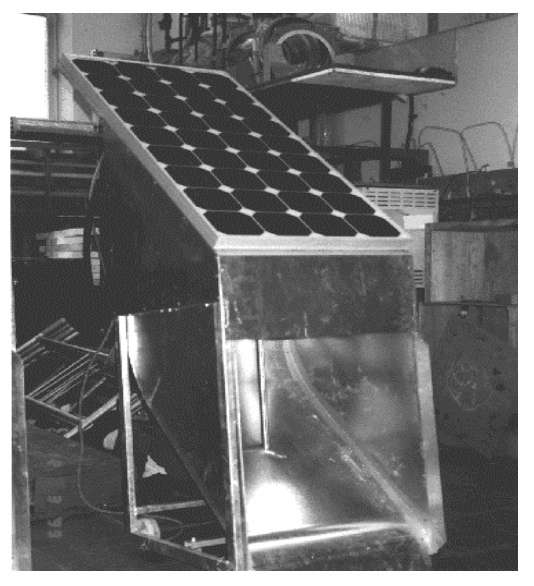

Figure 3 a picture of a prototype DWT.

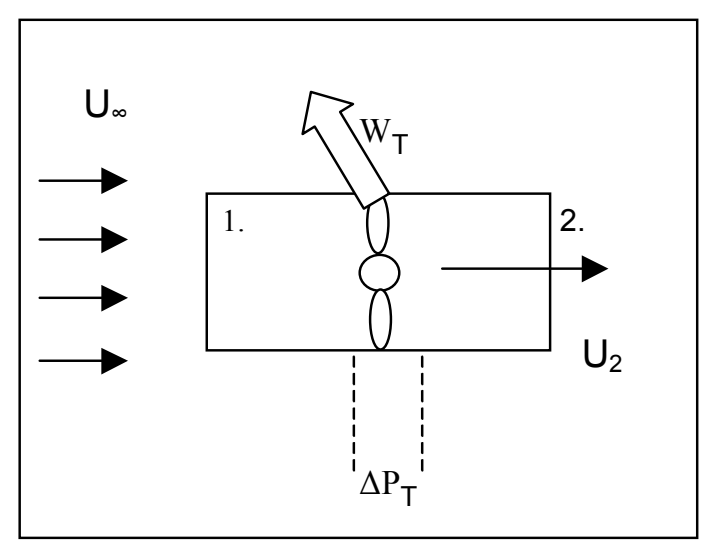

Figure 4 a simple model of a ducted wind energy conversion device. 


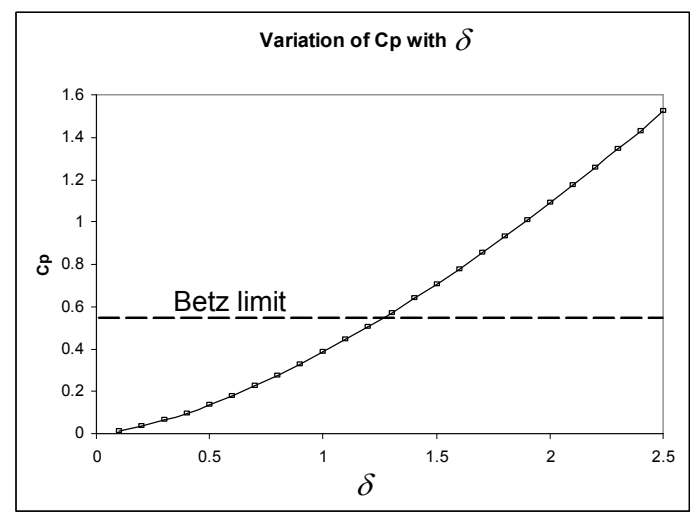

Figure 5 the variation of $C_{P}$ with $\delta$.

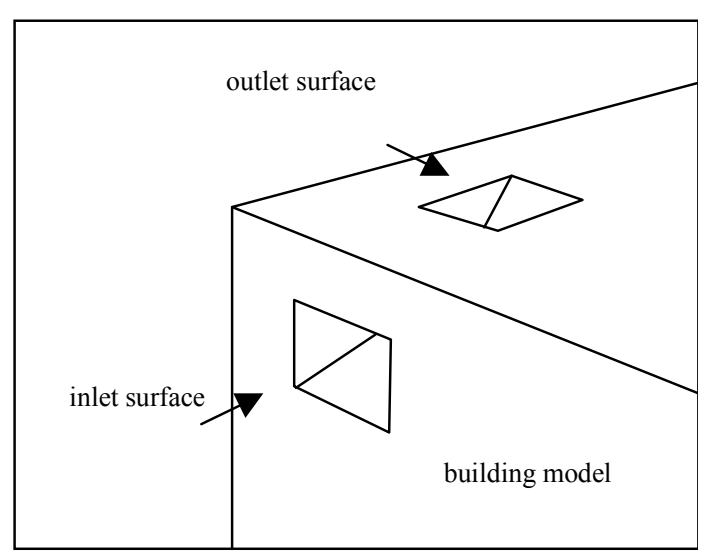

Figure 6 integration of the DWT model into a building model. 


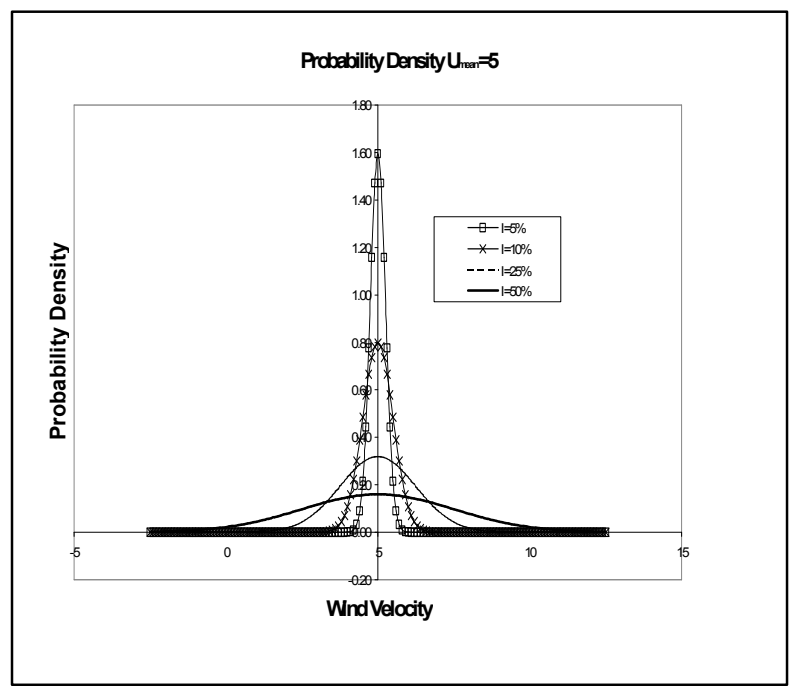

Figure 7 the effect of changing $I$ in Equation 23.

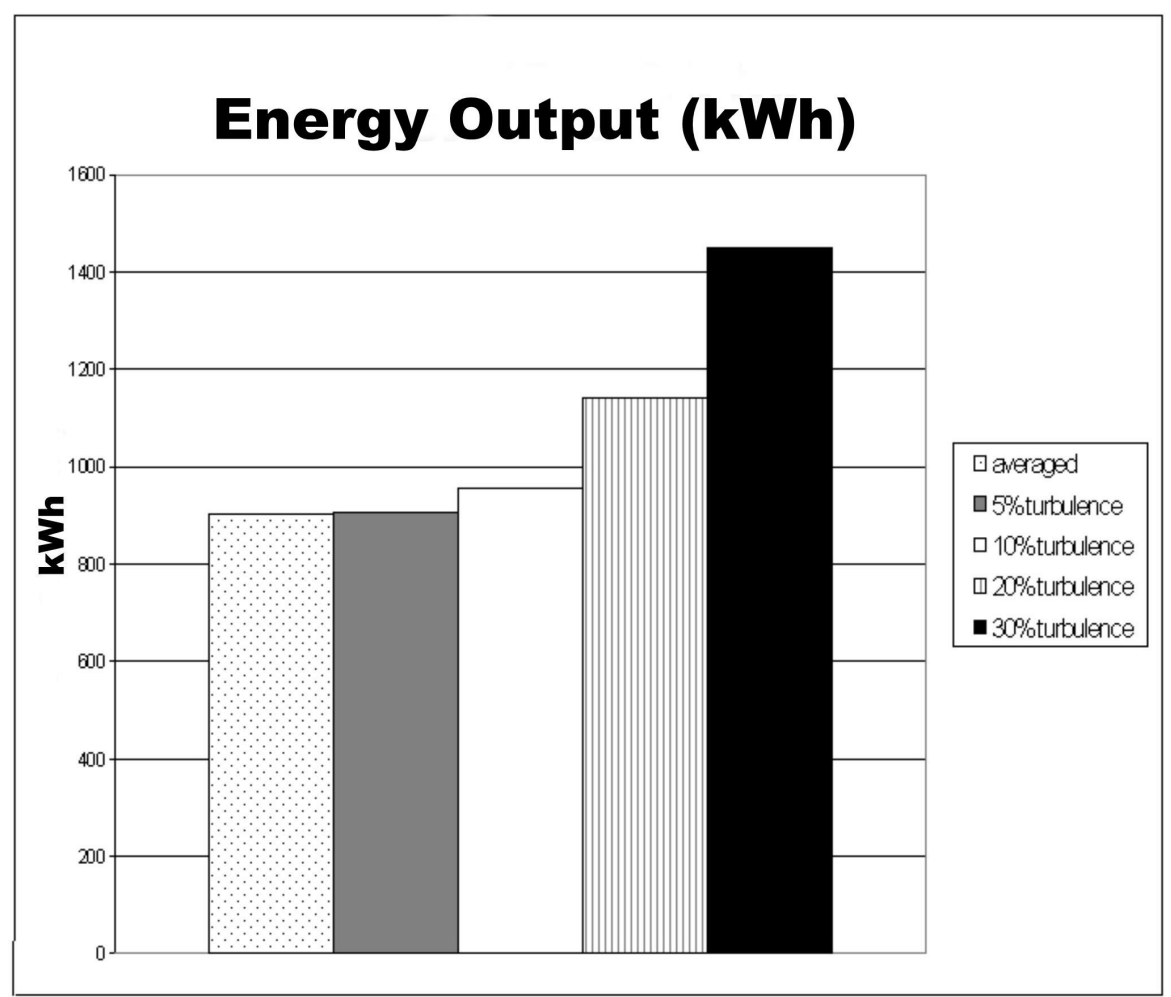

Figure 8 the energy output predictions. 


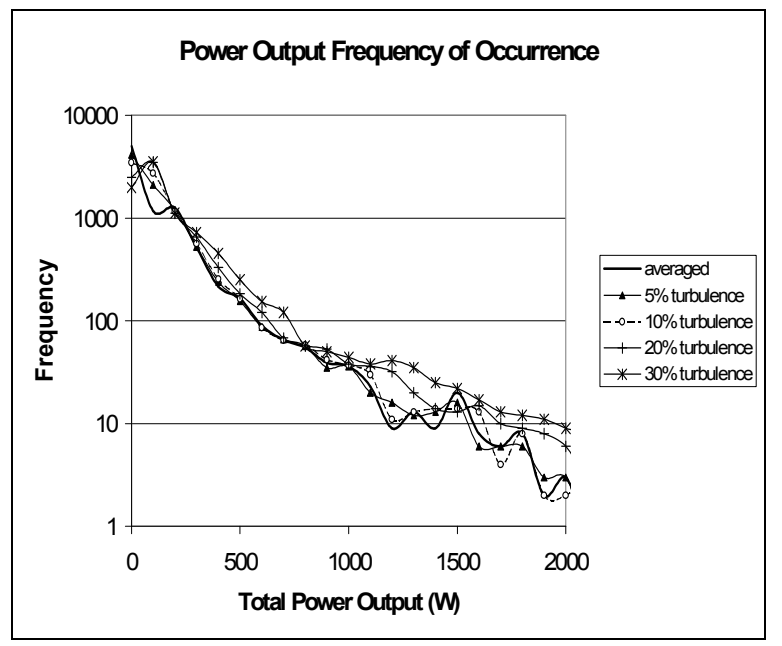

Figure 9 power output frequency distribution.

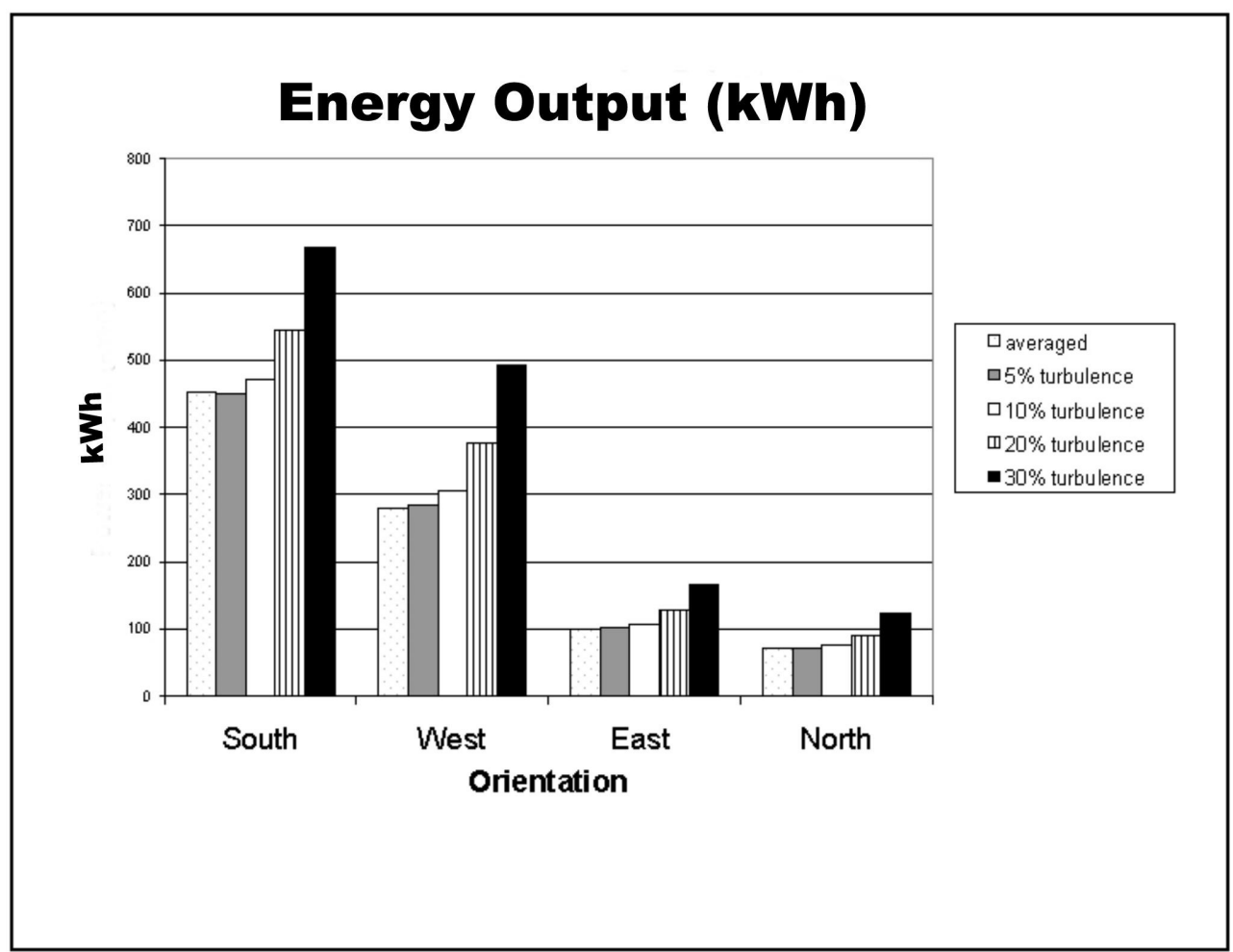

Figure 10 the contributions from the different facades to power production. 


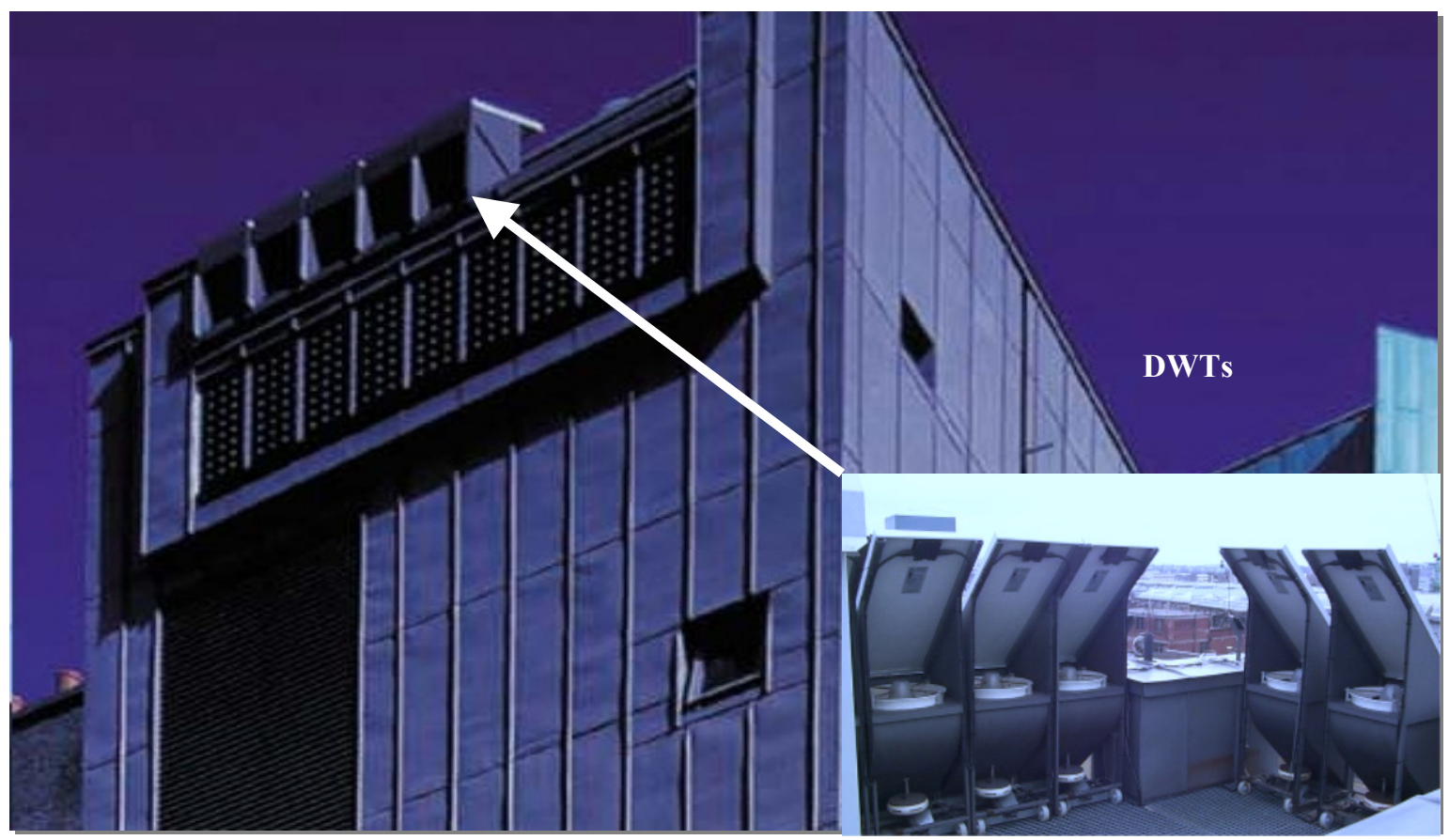

Figure 11 Ducted wind turbines on the Lighthouse building, Glasgow. 